\title{
The Value of a Dynamic Memory: from Heritage Conservation in Turin
}

\author{
Maurizio Marco Bocconcino \\ Mariapaola Vozzola
}

\section{Abstract}

The proposed contribution is the start of a research project on the conservation and care of the memory of urban contexts that are changing and that, while changing, it is desirable to preserve traces of past evolutions. These are particular areas of study, characterised by significant values that need to be known and passed on. Since the beginning of this year, the research group has been dealing with significant experimental cases. On this occasion, some quick elaborations and prefigurations of documentary integration with the existing heritage will be presented for the case of the Borgo Crocetta nursery school building in Turin.

Keywords

cultural and environmental heritage, expeditious urban survey, memory conservation, graphic codes.
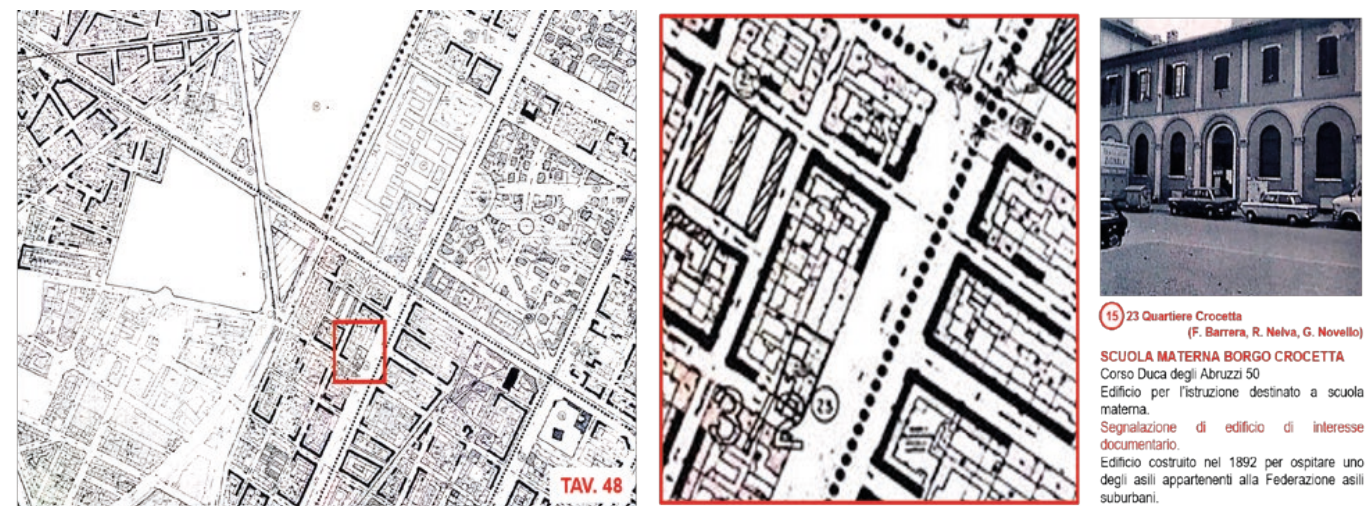

(15) 23 Quartiere Crocettla $($ F. Barrora, R. Nelva, G. Novello) SCUOLA MATERNA BORGO CROCETTA Edfifcio per listruzione destinato a scuola Sagnalazione di edificio di inleresse
socumentario Edificio costruito nel 1892 per ospitare uno
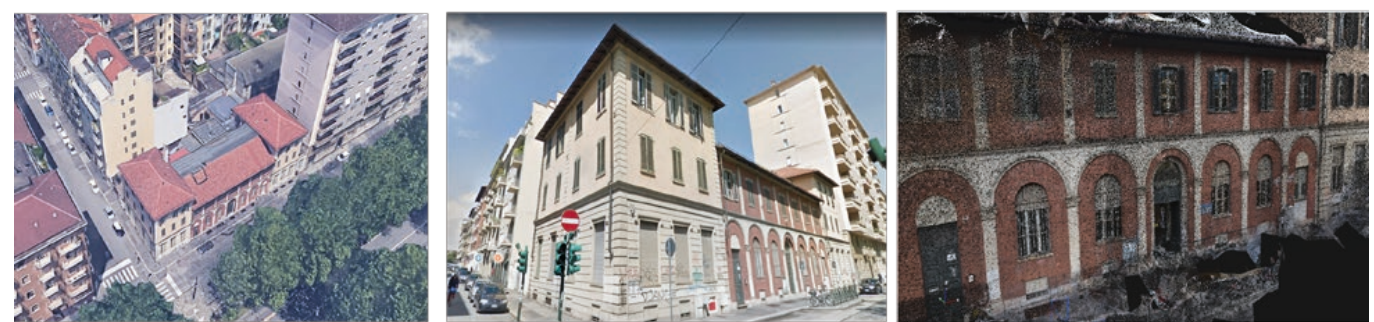


\section{The Study of the Cultural Environmental Heritage of Turin (1984)}

The analysis of urban form and the architectural-environmental identity of the built city are themes addressed in various research experiences conducted in the Turin area by many well-known scholars. The experience of the census of the cultural and environmental heritage of the City of Turin has given substance to general urban planning instruments consolidated for Turin in subsequent years and it is now being updated.

In this contribution, we will look at an important aspect of this census, at how digital resources and archives keep alive its cognitive function, at some possibilities of integration that collaborate with the methodological application of the research begun in the 1980s, and finally, we will share some considerations that should support the continuation of our future work.

At the beginning of the 1980s, on the occasion of the revision of its general regulatory plan, the City of Turin promoted research and studies concerning the complexity of its articulated urban system and the scientific approaches necessary to govern its transformation processes. These researches have been carried out by organisations of scientific importance and, in particular, the Politecnico di Torino, under an agreement with the City, has identified, recognised, and classified the architectural and environmental cultural heritage of the entire municipal territory.

The foundation of the identification and classification work was the regional town planning law (L.R. 56/77) and the preparatory studies for the town plan entrusted to Gregotti and Cagnardi (1995). A very broad research team, coordinated by ProfessorVera Comoli, which mainly involved two Departments, one from the Architecture area, the House and City Department, and one from the Engineering area, the Department of Building and Territorial Systems; for the engineering area, the area from which we come, there were Pina Novello, Riccardo Nelva and Paolo Scarzella.

As Vera Comoli wrote in introducing the study: "The research uncovers a very articulated and diffuse consistency of the environmental cultural heritage, much more extensive and analytical than the traditional binding recognition, much more differentiated according to cultural specificities, values, and implicit values" (AA.W. 1984, p. 28).

The methodological approach also involved the identification of a graphic language and representation codes based on municipal technical cartography. The work on Cultural and Environmental Heritage represents a very in-depth field of investigation, especially in the reading of its relationship with the city.

One aspect that has emerged is the importance of investigating ways of preserving memory before intervention in areas of special interest transforms their functional and formal aspects while preserving the identity and recognised elements. In the current state of the art, it is of substantial interest to understand how to implement and update the information collected in the study, published in 1984, to make the permanence of those considerations, updated, accessible in a dynamic way within the information systems dynamically accessible within the existing information systems.

Within the study merged in the publication, a different degree of compatibility with urban transformations was identified to define and order three categories of values linked to protection constraints graded according to the hierarchy of the specific urban quality: assets of historic-artistic value, assets of environmental and/or documentary value, signs of cultural and/or documentary significance or interest. Assuming the criterion of active protection and environmental safeguarding and restoration for all categories of assets, for the for first two the type of eligible interventions is strictly limited.

On the other hand, intervention is possible in areas of cultural and/or documentary interest (segnalazioni). In fact, after exhaustive documentation and critical analysis, in-depth transformations can be prefigured, but "sectorial, casual, in any case disqualifying interventions cannot be accepted". We are focusing our interest on this type of property as part of an ongoing experiment.

We think that the mediation of traditional representation tools is experiencing a renewed development and breath through today's ways of support and treatment offered by the 
methodologies and technologies produced by information science; these allow many data to be organised using in-depth analysis and digital representations with different and articulated levels of detail.

The sphere of the 'segnalazioni' assets, for the type of interventions that it allows, makes it possible to exploit methodologies and technologies that make the paths of preservation of memory more agile and keep their presence dynamic; the mediation of the traditional tools of representation lives a renewed development and breath through updated methods for the support and treatment of data; methods that, through the technologies produced by the science of information, allow to organize many elements of knowledge with insights and digital representations with a different and articulated level of detail, integrated into the computer tools that institutions are increasingly sharing (fig. I).

\section{Methodological Aspects and Initial Scope of Application}

The development of integrated digital archives, in which easy access to all types of cultural heritage is made possible, with interactive and hypertextual navigation between the assets themselves, is a significant development. For their implementation, it is necessary to set up a digital inventory complete with databases of real and virtual assets, acquiring digital images with descriptive cards, creating digital images and virtual descriptions, and, where possible, inserting descriptions and three-dimensional representations of the asset, obtained with the most appropriate survey techniques.

Through the selection of a first representative and significant case of the category of assets described above, it is possible to compare the most effective and efficient ways

Fig. I.The case study is based on the analysis of the available documentation. The figure shows a graphic summary Muse contents on the the Geoporta of the City the Geoportal of the City ofTurin.

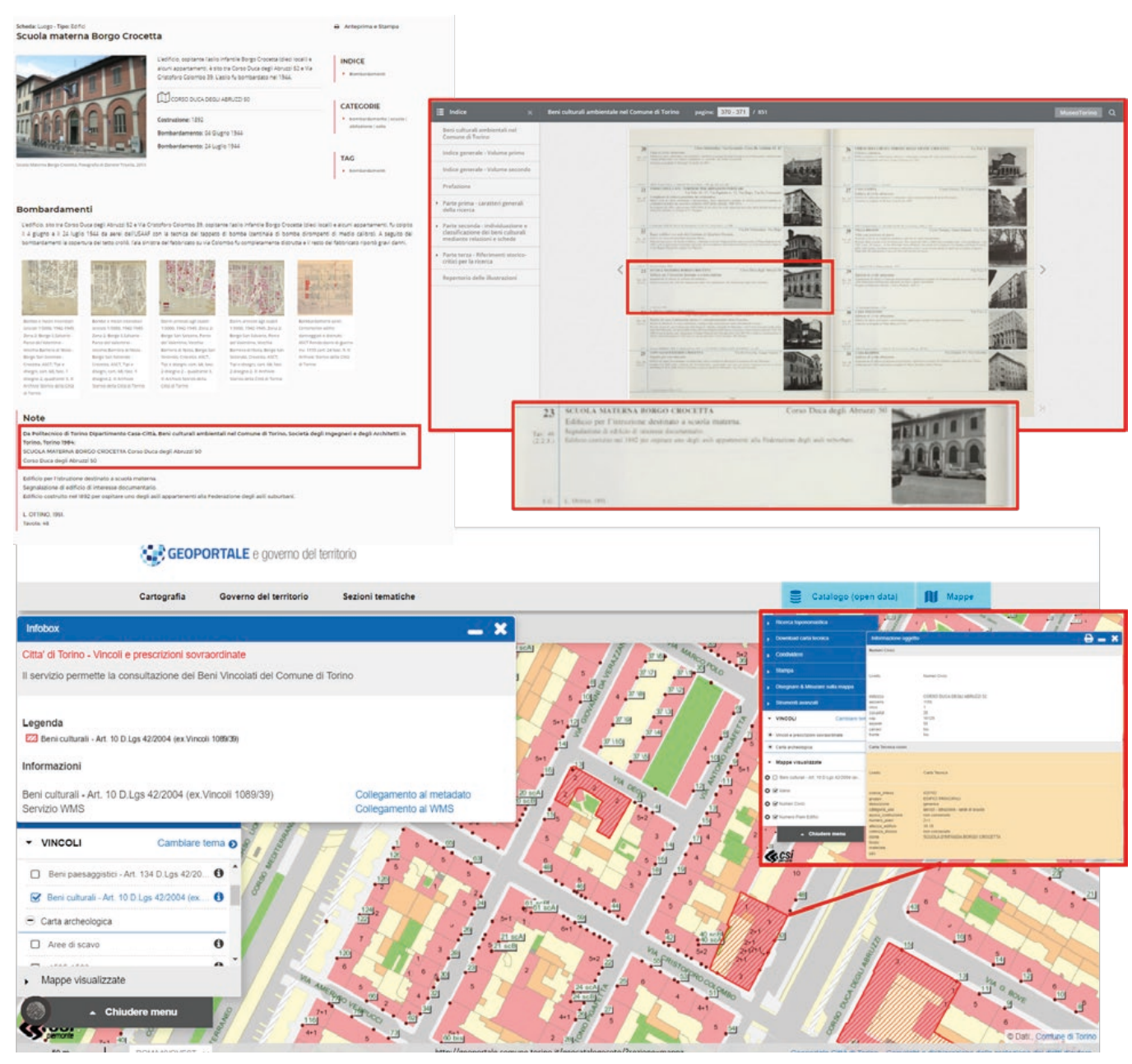


of consultation, which are not limited to orderly cataloging but incorporate processes of an expeditious survey and automatic and 'intelligent' restitution (photo modeling). This is the step that has to be taken to support the management of a multi-relational database, whose information potential is increased by geometric-spatial and textual-numerical dimensions, suitable to be implemented to define, record, disseminating, and processing data and information characterised by individual and contextual specificities.

The 'segnalazioni' of urban areas of environmental and/or documentary interest indicates buildings and aggregates of the city which constitute significant evidence of a determined historical period and a particular cultural season or possess intrinsic values for a physical and functional improvement aimed at raising the urban quality. In figure 2 some elaborations were carried out on the Borgo Crocetta school building in Turin, which represents an example of 'segnalazioni'.

The case study is based on the analysis of the available documentation and investigates more interactive tools that bind knowledge within graphic containers. The knowledge supports for Turin have for years been stratified in photographic images and maps that are rapidly accessible and consultable, semantic digital archives, Plan instruments and general urban planning instruments.

The existing wealth of information can be supplemented by expeditious and digital surveys, from the photo modeling of the context and of the building at the urban scale, to the instrumental detection of architectural details that can be properly interpreted by artificial intelligence tools and then be integrated into digital information models. By definition, augmented reality offers users the possibility to integrate virtual objects in three dimensions into their living environment in real-time. But there are different ways to do this, including marker-based, or markerless solutions based on global positioning systems (GPS). Solutions based on 'markers', or on location or scene recognition, respond to the sensors of mobile devices and allow multi-dimensional information to be placed in a given location. The stratifications of indications have followed different skills over time. Their sedimentation can be observed today in the information system of the City of Turin. In this case we observe a partial deficiency, missing an element of connection between studies made, collected in part, and those currently present. In this sense, it will be necessary to pose the issue of criticism and self-criticism on the updates of the Cultural and Environmental heritage, starting from the registration of the size of the urban fabric while recognising the architectural and building value. Furthermore, it will be necessary to create consultation tools that are more ductile and easier to consult and update the data: census resulting from a survey linked to the design of areas linked to the Cultural and Environmental Heritage, producing materials according to standard protocols to support the administrations to verify the reuse of shared data and evaluate integrations.

\section{Concluding Remarks and Future Developments}

Integration into the multiplicity of levels referred to must be supported by appropriate dissemination tools; the dimension of the mutations inherent in the same part of the territory investigated in the future or documented through materials of different origin or temporal

Fig. 2. Spatial survey for memory. More 'intelligent' tools that combine knowledge within dynamic graphica containers.

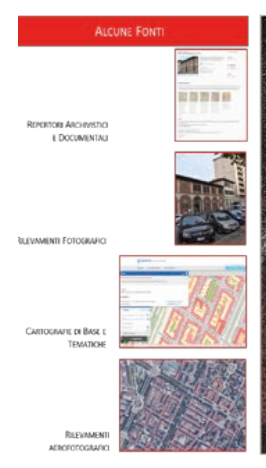

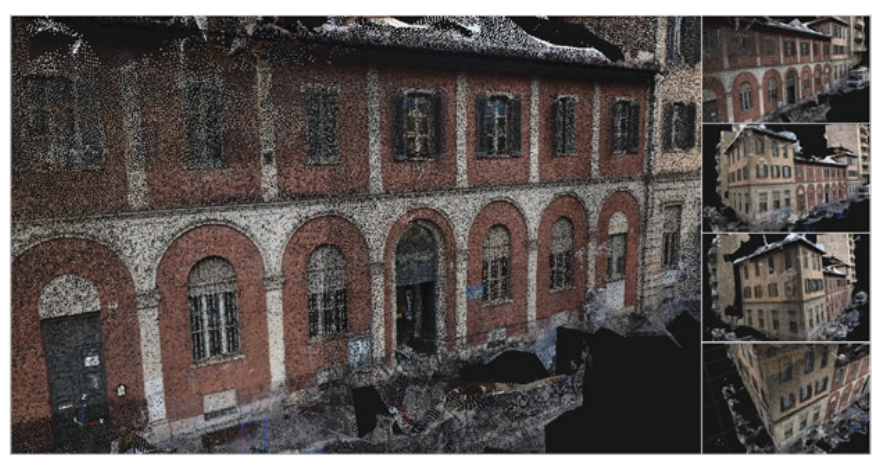

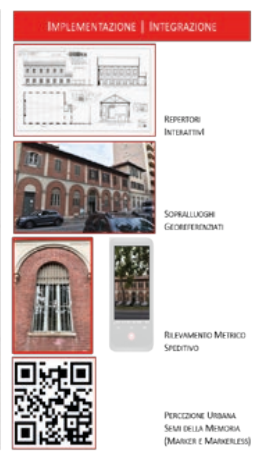


derivation is a relevant aspect, just as the heritage of elaborations contained in the research should not be dispersed, or ignored, if we want to encourage an active and dynamic memory for those significant parts of assets and contexts which, although modified or redefined by interventions made necessary over time, could be kept alive and present in virtual scenarios, in order not to forget their primitive value and integrating the different possible forms of reading and interpretation.

The setting up of a recognisable and still valid method, whose application today is confronted with analysis and recording tools that are more agile and above all more accessible to diversified users with a high degree of accessibility, is today measured by the dematerialisation of knowledge. It is necessary to recognise technologies that are easy to use so that they can be applied widely and homogeneously, technologies that multiply, but above all go beyond, in the permanence of criteria and standards relating to the data and metadata to be stored: the ambition to 'put everything together and in relation' as an interpretation of a problem that derives from alternative technological knowledge that supports information intentions. In this sense, several questions will have to be addressed in the continuation of this research work which has just begun: How should information be managed, does it make the tools chase or does it chase them? How to 'seed' urban memory, material identifiers or global positioning systems?

We are confronted with this: the transformation has taken place and that place today cannot tell its memory, its memory is mute or not everyone can understand it or can interpret it. The paradigm of what urban memory can lose and not transmit through the place itself, in the very place where it was produced, and not only through documentary heritage and archived knowledge, by their nature not accessible to a wide public, not consultable by walking those streets. One can only feel the distant sense of the human and urban reality that occupied that space in the past, but not visualise it, explore it at a distance of time. The seeds of memory need to be planted where memory is constantly being renewed, lost and reformed. The material that constitutes cities must therefore be used to narrate their transformation

\section{Acknowledgements}

The present research started under the scientific coordination of professor Giuseppa Novello, former researcher in the original BCA Turin working group, to whom we owe the constant confrontation in many of the critical considerations outlined above.

\section{References}

AA.V. (1 984). Beni culturali ambientali nel Comune di Torino.Torino: Società degli ingegneri e degli architetti in Torino, Politecnico di Torino. Dipartimento Casa Città. https://www.museotorino.it/resources/pdf/books/ I 5 I/ ( I March 202 I).

Garzino Giorgio, Novello Giuseppa, Bocconcino Maurizio Marco (2018). Handbook of Research on Urban and Territorial Systems and the Intangible Dimension: Survey and Representation. In Inglese Carlo, Ippolito Alfonso (eds.) Conservation, Restoration, and Analysis of Architectural and Archaeological Heritage. Hershey, Pennsylvanie, USA: IGl Global, pp. 346-385.

Novello Giuseppa, Bocconcino Maurizio Marco (2018). New methods for the dissemination of the research on the city: multimedia tools for the sharing of documentary archives / Nuovi metodi per la diffusione delle ricerche sulla città: strumenti multimediali per la condivisione degli archivi documentali. In DISEGNARECON, I I (2 I), pp. I- I4.

Novello Giuseppa, Bocconcino Maurizio Marco (2019). Dalle mappe ai sistemi informativi.Lungo le rotte del Disegno navigando nell'arcipelago delle esperienze di un gruppo di ricerca (1974-2019) - From Maps to Information Systems Along the Routes of the Drawing Navigating in the Archipelago of the Experiences of a Research Group (1974-2019). In Diségno, 5, pp. 33-44.

Novello Giuseppa, Bocconcino Maurizio Marco (2020). Itinerari digitali tra carte e disegni del patrimonio dell'archivio Porcheddu. Le pratiche delle opere torinesi nel periodo 1894-1927. In History of Engineering Storia dell'Ingegneria 4th International Conference Atti dell'8 Convegno Nazionale, Napoli, pp. 633-654.

\section{Authors}

Maurizio Marco Bocconcino, Dept.of Structural, Geotechnical and Building Engineering, Politecnico di Torino, maurizio.bocconcino@polito.it Mariapaola Vozzola, Dept. of Structural, Geotechnical and Building Engineering, Politecnico di Torino, mariapaola.vozzola@polito.it 
